\title{
Designing to TEDI, TEUI, and GHGI Performance Metrics
}

\author{
Jeanie Chan, Andrea Frisque, Anika Jang \\ Stantec Consulting Ltd., Vancouver, Canada
}

\begin{abstract}
The City of Vancouver (CoV) strives to become the Greenest City. This includes eliminating its dependence on fossil fuels. Recently, the City has introduced the new Green Building Policy for Rezoning (City of Vancouver, 2018), The policy mandates that buildings must either meet select $3^{\text {rd }}$-party certifications (e.g. Passive House, Living Building) or stringent energy use and emission targets: Total Energy Use Intensity (TEUI), Thermal Energy Demand Intensity (TEDI), and Greenhouse Gas Intensity (GHGI) performance limits. In our work, we have analyzed cost-effective design solutions for achieving these performance limits, using Parametric Design Analysis (PDA), for a mixed-use recreational facility that includes a pool, gym, multipurpose, and residential spaces. This paper presents how this new policy has altered best practices in building design, the design challenges of meeting these performance limits, how Parametric Design Analysis was used to find optimal solutions, and the innovative cost-effective solutions that were proposed and implemented into the design.
\end{abstract}

\section{Introduction}

\section{City of Vancouver's Green Buildings Policy for Rezoning}

The City of Vancouver's Green Buildings Policy for Rezoning is part of the Greenest City 2020 Action Plan. This plan was developed from 2009-2011 by local experts and city staff. The goal for Green Buildings is to "lead the world in green building design and construction" (City of Vancouver, 2015) with the targets of reducing energy use and GHG emissions by $20 \%$ (compared to 2007 levels) and by requiring all buildings constructed in 2020 and after to be carbon neutral.

The Green Rezoning Process was first adopted in 2010. Since then, it has been updated with more options and tighter requirements. The original goals of the policy were to 1) increase the number of third-party certified Green Buildings; 2) transform the market by increasing consumer awareness and choice for Green Buildings; 3 ) develop a process that works for industry to rezone their property; and 4) nurture the growing Green Building industry in Vancouver.

In 2017, there was a major overhaul of the policy, including an update to the name: The Green Buildings Policy for Rezoning. The new policy offers two paths: Near Zero Emissions Buildings or Low Emissions Green Buildings (City of Vancouver, 2018). Near Zero Emissions Buildings requires the project to meet and apply for Passive House certification or a similar net zero standard. Alternatively, the Low Emissions Green Buildings involves the following building performance requirements: 1) LEED Gold Certification and 2) Performance Limits on the TEUI, TEDI, and GHGI. Each limit is intended to drive the building design in a certain direction: The TEDI limit encourages the design to have a high-performance building envelope, a high level of airtightness, and heat recovery ventilation; GHGI favors building systems that use electricity over fossil fuels; and finally, the TEUI limit promotes overall low energy use. The follow equations show how each metric is calculated for a project:

$$
\begin{aligned}
& \text { TEUI }\left[\frac{k W h}{m^{2} y r}\right] \\
& =\frac{\sum \text { Site Energy Use }\left[\frac{k W h}{y r}\right]-\sum \text { Site Renewable Energy Generation }\left[\frac{k W h}{y r}\right]}{\text { Modelled Floor Area }\left[\mathrm{m}^{2}\right]} \\
& \text { TEDI }\left[\frac{k W h}{m^{2} y r}\right]=\frac{\sum \text { Space and Ventilation Heating Output }\left[\frac{k W h}{y r}\right]}{\text { Modelled Floor Area }\left[\mathrm{m}^{2}\right]} \\
& \text { GHGI }\left[\frac{\mathrm{kgCO} \mathrm{O}_{2 e}}{\mathrm{~m}^{2} y r}\right] \\
& =\frac{\sum\left(\text { Site Energy Use }\left[\frac{\mathrm{kWh}}{\mathrm{yr}}\right] \times \text { Emissions Factor }\left[\frac{\mathrm{kgCO}}{\mathrm{kWh}}\right]\right)}{\text { Modelled Floor Area }\left[\mathrm{m}^{2}\right]}
\end{aligned}
$$

Currently, the policy has two sets of performance limits, those for buildings connected to a City-recognized Low Carbon Energy System and those not connected (Table 1), which is the most common.

Table 1: Performance Limits for Buildings not Connected to a City-recognized Low Carbon Energy System.

\begin{tabular}{|c|c|c|c|}
\hline Building Type & $\begin{array}{c}\text { TEUI } \\
(\mathbf{k W h} / \mathbf{m} 2)\end{array}$ & $\begin{array}{c}\text { TEDI } \\
(\mathbf{k W h} / \mathbf{m} 2)\end{array}$ & $\begin{array}{c}\text { GHGI } \\
(\mathbf{k g C O 2} / \mathbf{m} \mathbf{2})\end{array}$ \\
\hline $\begin{array}{c}\text { Residential } \\
\text { Low-Rise } \\
\text { (<7 storeys })\end{array}$ & 100 & 15 & 5 \\
\hline $\begin{array}{c}\text { Residential } \\
\text { High-Rise } \\
(>7 \text { storeys })\end{array}$ & 120 & 30 & 6 \\
\hline Office & 100 & 27 & 3 \\
\hline Retail & 170 & 21 & 3 \\
\hline Hotel & 170 & 25 & 8 \\
\hline $\begin{array}{c}\text { All Other } \\
\text { Buildings }\end{array}$ & $\begin{array}{c}\text { EUI 35\% better than Building By-law } \\
\text { energy efficiency requirement }\end{array}$ \\
\hline \multicolumn{4}{|l}{} \\
\hline
\end{tabular}

For mixed-use buildings, the TEUI, TEDI, and GHGI limits are a combined area weighted average of the performance limits for each building type. The portions of the building that have a TEDI target must also meet their combined TEDI target (City of Vancouver, 2018).

\section{Parametric Simulations}

In recent years, parametric simulations have made great strides forward in whole-building energy simulation. They are now routinely used in the building design process for new construction. They provide an 
opportunity to evaluate a vast array of design options and find the optimal solution for any given performance or cost targets.

Parametric simulations have also been used to analyze energy efficiency measures (EEMs). For example, Attia et al. (2012) have developed a simulation-based decision support tool for the early stage design of zero-energy buildings. It utilizes EnergyPlus based parametric simulations to optimize passive (e.g. orientation, geometric features, envelope properties) and active (e.g. HVAC, ventilation, photovoltaic, solar thermal) building elements. Parker et al. (2014) present a workflow utilizing the OpenStudio Parametric Analysis tool to analyze EEMs. Al-ajmi et al. (2017) uses TRNSYS-PREBID to perform a parametric sensitivity analysis of EEMs relating to building envelope, window type, size and direction, infiltration, and ventilation. Kerdan et al. (2015) have used EnergyPlus based parametric simulations to assess the impact of retrofit measures (e.g. HVAC systems, insulation) for office and primary school type buildings. In their study, they have proposed a multiobjective optimization method to find the optimal retrofit measures that minimize energy use, exergy destructions, and thermal discomfort. Lee et al. (2015) have created DEEP (database of energy efficiency performance) for commercial buildings in California using EnergyPlus. They have explored EEMs covering envelope, lighting, heating, ventilation, air-conditioning, plug-loads, and service hot water. DEEP is integrated into a web-based retrofit toolkit, which queries the database and returns recommended EEMs as well as their estimated energy savings and simple payback. Iqbal et al. (2007) have studied EEMs (i.e. HVAC systems, glazing, insulation, temperature setpoints, and lighting) in Visual DOE 4.0 for an existing office building in Saudi Arabia. Optimal EEMs were chosen solely based on energy conservation.

In our work, we have developed a process for finding cost-effective solutions for retrofit or new construction projects (Chan et al., 2018). Our process is designed to clearly identify the tasks of the energy modeller as well as the inputs and deliverables for each task. It is also designed to provide sufficient data and recommendations to inform decision makers of the best design measures or combination of measures to implement. This process builds upon the use of parametric simulations to optimize design by adding financial analysis and a user-friendly and interactive interface to analyse the parametric results. In this paper, we have applied this process to find design solutions for achieving all three performance limits for a mixed-use recreational facility that includes a pool, gym, multipurpose, and residential spaces.

\section{Methods}

An energy model that represents the proposed form and geometry of the building is created, as the basis for applying possible mechanical, electrical and envelope options. The options range from typical standard construction to the highest passive standard. Each option is subject to careful analysis, modelling, life cycle analysis and ongoing review with the client team. The general process of our analysis is as follows:

1. Energy Model of Proposed Design

2. Design Measure Selection

3. Parametric Design Analysis (PDA)

Each of these steps is described in more detail in the following sections. Through this process, sufficient data and recommendations can be developed to inform decision makers of the best design upgrade measures or combination of measures to implement.

\section{Energy Model of Proposed Design}

Energy analysis using simulation software can be very valuable throughout the design of new buildings to estimate the energy use of a future building design based on the local climate characteristics, system choices, and geometry. The purpose of energy simulations is to develop an energy balance calculation of the various energy flows in the building. Knowing where the energy is used in the building allows one to identify opportunities to reduce the energy use in a design. Successful highperformance buildings can only be achieved by understanding how building components interact under operating conditions.

Our approach is to create an energy model of the proposed design based on the architectural, mechanical, and electrical drawings/documentation of the proposed design.

\section{Design Measure Selection}

The number of design upgrade measures imaginable are countless; however, many of them do not pass an initial viability test. To establish a list of plausible measures, we have implemented a selection strategy based on several objectives. The following objectives guide the measure selection process and form the basis of their evaluation:

- Provide best value based on professional judgement and experience

- Utilize proven technology

- Reduce energy consumption by first focusing on large scale measures

- Select measures based on ease of maintenance

- Minimize capital investment where appropriate

- Select measures that save energy in the largest energy consumers

The energy and cost impact of these measures will be evaluated via Parametric Design Analysis.

\section{Parametric Design Analysis}

In recent years, energy simulation technologies have advanced to enable a review of the interactive effects of multiple measures implemented simultaneously. This process is called Parametric Design Analysis (PDA). The analysis consists of the following three steps:

\section{Parametric Simulation}

In the first step, rather than narrowing down the potential designs to a small subset of designs and/or energy efficiency measures to be analyzed through simulation, potential design options are created by combining all of the different design parameters that are conceivable for 
the project. This means that many design iterations are created, typically including envelope performance, HVAC system, lighting design, and any other design consideration of interest, which are combined in various permutations. Whole building energy simulations using each design iteration can be performed using parametric simulations in IES Virtual Environment (IESVE) 2015. Using this process of parametric simulations limits the need to reduce the number of simulations to a manageable number as the only limitation is computational power. This enables the design team to estimate the impact of all individual design decisions on the overall building energy performance.

\section{$\underline{\text { Parallel Coordinates Tool }}$}

The parametric simulations generate a very large number of results data as they efficiently perform hundreds or thousands of full individual energy models. To be able to gain information from the data and draw conclusions, the data needs to be processed with a tool suitable for large sets of multi-dimensional data. The parallel coordinates tool can present this data in an interactive way, where sets of parameters can be chosen to view an outcome of interest such as energy use intensity (EUI), net present value (NPV), or payback period. The parallel coordinates tool utilizes the open-source JavaScript library d3.parcoords.js.

\section{Design Options Selection}

Using the parallel coordinates tool, Design Options (i.e. measure bundles) are selected based on the ability of a combination of individual measures to meet the project objectives, such as, for example, EUI, TEDI or GHG emissions targets. The power of the parallel coordinates tool lies in the ability to select the target outcome in the interactive data set and get, as a result, all the Design Options that would meet the performance targets. The most economical of these options can then be selected for implementation. Depending on the economic framework for a project, the most economically feasible option can be characterized by different metrics, for example, capital cost investment, simple payback, or a more sophisticated life cycle cost analysis.

\section{Results}

The building analysed in this study is a recreational facility with a residential tower. It is located in Vancouver, BC. The recreation building is a 14-storey building with a conditioned floor area of approximately $13,220 \mathrm{~m}^{2}$. There are also 3 underground levels, which consists of parking stalls, mechanical/electrical rooms, offices, and storage.

The building accommodates several space types such gymnasium, pool, fitness area, office, conference room, restroom, locker room, stairwell, lobby, corridors, residential suite, as well as other spaces to provide service to the building such as storage room, electrical and IT server room, and mechanical room.

\section{Energy Model of the Preliminary Design}

An energy model was created to reflect the geometry and key design features of the preliminary design (Table 2).
Table 2: Key Features of the Preliminary Design.

\begin{tabular}{|c|c|}
\hline $\begin{array}{l}\text { Building } \\
\text { Component }\end{array}$ & Preliminary Proposed Design \\
\hline Envelope & $\begin{array}{c}\text { Roof: R-20.8 (RSI 3.7) } \\
\text { External Walls: R-15.6 (RSI 2.7) } \\
\text { Windows: U-0.45 (USI 2.6) }\end{array}$ \\
\hline Lighting & $\begin{array}{c}\text { Fitness: } 1.0 \mathrm{~W} / \mathrm{ft}^{2}\left(10.8 \mathrm{~W} / \mathrm{m}^{2}\right) \\
\text { Gym/Multipurpose: } 1.2 \mathrm{~W} / \mathrm{ft}^{2}\left(12.9 \mathrm{~W} / \mathrm{m}^{2}\right) \\
\text { Pool: } 0 / 8 \mathrm{~W} / \mathrm{ft}^{2}\left(8.6 \mathrm{~W} / \mathrm{m}^{2}\right) \\
\text { Offices: } 1.11 \mathrm{~W} / \mathrm{ft}^{2}\left(11.9 \mathrm{~W} / \mathrm{m}^{2}\right) \\
\text { Residential: } 0.5 \mathrm{~W} / \mathrm{ft}^{2}\left(5.0 \mathrm{~W} / \mathrm{m}^{2}\right)\end{array}$ \\
\hline $\begin{array}{l}\text { HVAC: } \\
\text { central } \\
\text { system }\end{array}$ & $\begin{array}{l}\text { Cooling: heat recovery chiller } \\
\text { Heating: heat recovery chiller, backup gas- } \\
\text { fired boiler }\end{array}$ \\
\hline $\begin{array}{l}\text { HVAC: } \\
\text { zone level }\end{array}$ & $\begin{array}{l}\text { Recreation centre: VAV with reheat } \\
\text { Residential: Fan-coils, no cooling }\end{array}$ \\
\hline $\begin{array}{c}\text { Heat } \\
\text { Recovery }\end{array}$ & $\begin{array}{l}\text { Heat recovery chiller, exhaust air heat } \\
\text { recovery coils }\end{array}$ \\
\hline
\end{tabular}

Figure 1 shows a 3D rendering of the energy model. IESVE 2015 was the software used to model this building.

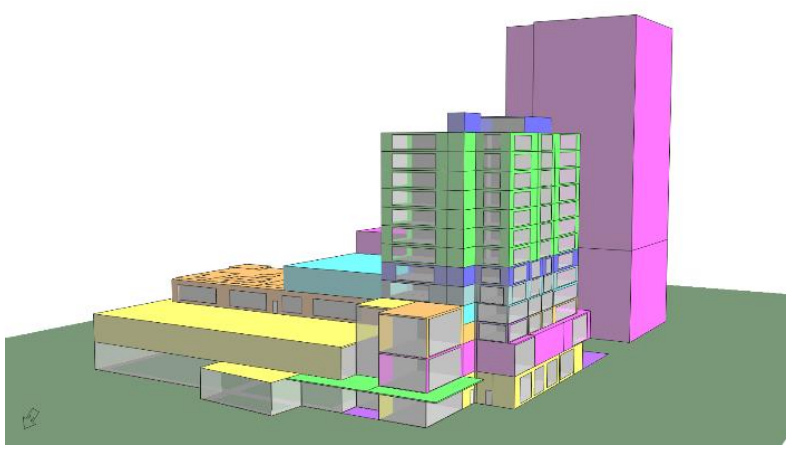

Figure 1:IESVE Model of the Proposed Design.

\section{Pool Calculations and Modelling}

The building includes five pools: 3 whirlpools, a lap swimming pool, and a warm pool. In order to accurately model the pool spaces and their effect on the surrounding environment, we performed external calculations and adjusted model inputs to ensure that energy flows were represented appropriately. Evaporative, convective, and conductive losses of the pool water to the space above are included in the model. Radiation losses are assumed to be minimal and are therefore not included in the model.

IESVE does not have a capability to explicitly model pools, but they have provided a workaround to model the convective heat losses from the water to the space above it (IES Virtual Environment, 2019). In the model, each pool is modelled as a separate space. To represent the water surface, the top of the spaces is modelled using a modified "window" element that acts like the surface of the water, with a heat transfer coefficient close to that of a water surface.

The latent heat gain to the air above the pool is calculated based on the rate of evaporation from the water surface. Equation 4 from the 2011 ASHRAE Handbook - HVAC Applications - Section 5.6 is used to calculate the evaporation rate, using a typical Activity Factor of 0.5 during unoccupied time and 1.0 while occupied. 


$$
w_{p}=4 \times 10^{-5} A\left(p_{w}-p_{a}\right) F_{a}
$$

Where:

$w_{p}=$ evaporation of water, $\mathrm{kg} / \mathrm{s}$

$A=$ area of pool surface, $m^{2}$

$p_{w}=$ saturation vapour pressure taken at surface water temperature, $\mathrm{kPa}$

$p_{a}=$ saturation pressure at room air dew point, $\mathrm{kPa}$

$F_{a}=$ typical activity factor

The building owners expect that the lap pool to be in operation for 16 hours each day and the whirlpool and warm pool to be in operation for 15 hours a day. The evaporation rate is then multiplied by the heat of evaporation of water to get the latent heat loss. Latent gains in the pool space were calculated for occupied and unoccupied times. These values were added as a latent gain to the pool space.

To estimate the water heating energy required for the pools, those same evaporation rates were used to find the daily water loss from each pool. Using the incoming water temperature and the specific heat of water, we calculated how much energy would be required to heat the water used to refill the pool. The pool is also assumed to be emptied, cleaned and refilled once a year.

A heater was modelled in each pool in order to estimate the amount of energy it would take to maintain the required pool water temperatures. The mass factor of the space was changed to the specific heat capacity of water.

\section{CoV Performance Limits for Mixed Use Buildings}

This building has both residential areas and nonresidential areas, so it falls under the requirements for mixed-use buildings. This means that the TEUI, TEDI, and GHGI limits are a combined area weighted average of the recreational spaces and residential tower limits (City of Vancouver, 2018). The residential tower also must meet the TEDI requirement for "Residential High Rise".

The recreational spaces of this building falls under the "All Other Buildings". Therefore, the performance limits of those spaces are determined based on the Vancouver Building By-law (VBBL) energy efficiency requirements. At the time of the rezoning application, the VBBL energy efficiency requirement is to comply with either ASHRAE 90.1-2010 or NECB 2011 energy code. An ASHRAE 90.1-2010 baseline model was created to determine the TEUI, TEDI, and GHGI targets for the recreational spaces. This model only contains recreational facility space types and does not include the residential portion of the building. The TEUI performance limit for the recreational space types is $35 \%$ lower than the baseline model TEUI. The TEDI and GHGI performance limits are the baseline model TEDI and GHGI. Table 3 show the performance limits for the residential spaces, recreational spaces, and whole building. In summary, the proposed building has to meet the TEUI, GHGI, and TEDI requirements for the whole building, as well as the TEDI requirement for the residential spaces.
Table 3: Performance Limits for the Building.

\begin{tabular}{|c|c|c|c|}
\hline Metric & $\begin{array}{c}\text { Residential } \\
\text { High Rise }\end{array}$ & $\begin{array}{c}\text { Recreational } \\
\text { Spaces }\end{array}$ & $\begin{array}{c}\text { Whole } \\
\text { Building }\end{array}$ \\
\hline $\begin{array}{c}\text { TEUI } \\
\left(\mathrm{kWh} / \mathrm{m}^{2}\right)\end{array}$ & 120 & 461 & 316 \\
\hline $\begin{array}{c}\mathrm{GHGI} \\
\left(\mathrm{kgCO} / \mathrm{m}^{2}\right)\end{array}$ & 6 & 96 & 58 \\
\hline $\begin{array}{c}\mathrm{TEDI} \\
\left(\mathrm{kWh} / \mathrm{m}^{2}\right)\end{array}$ & 30 & 280 & 174 \\
\hline
\end{tabular}

\section{Heating \& Cooling Load Analysis}

The heating and cooling load breakdown of the preliminary design was analysed in order to determine the key energy consumers. Since the biggest energy use of a building is space conditioning, this analysis gives us a good understanding of where we can potentially improve the building design with the aim of meeting the performance limits.

A significant portion of the heating and cooling load is attributed to the pool space in the building. A lot of energy is used to heat the pool water, as well as condition and dehumidify the space. Figure 2 shows a breakdown of the heating load in the building. $63 \%$ of the heating load is from heating the pool water and space heating for the pool area. The space heating load of the building directly relates to the TEDI and GHGI. The pool space has such a high thermal demand because it is a large space with high air change requirements (i.e. 3-5 air changes per hour). It also has a heating setpoint of $28^{\circ} \mathrm{C}$. This high heating load could potentially result in a high GHGI if a natural gas heating system is used; the $\mathrm{eCO}_{2}$ emission factor for gas is significantly higher than electricity. This could make it potentially challenging to meet the TEDI and GHGI requirements for this building without some form of heat recovery.

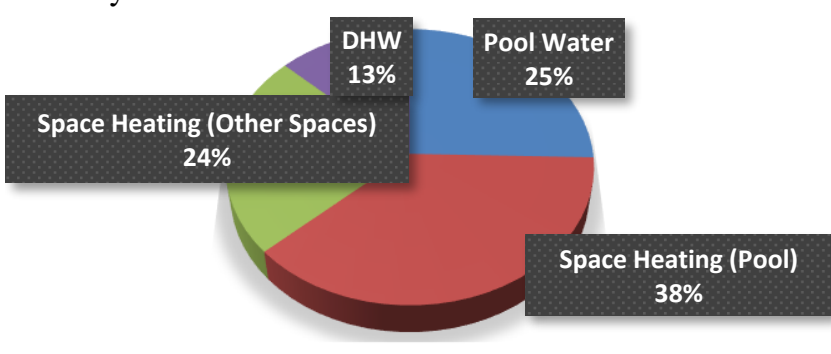

\section{Figure 2: Recreation Building: Heating Load Breakdown.}

The pool water load is further broken down into losses due to convection, conduction, and evaporation (Figure 3 ). Pool water is assumed to be refilled as needed due to overflow and evaporation, as well as a full refill once a year. Currently, evaporation makes up $82 \%$ of the total pool water load. The high evaporative losses to the pool space results in a high dehumidification load. 


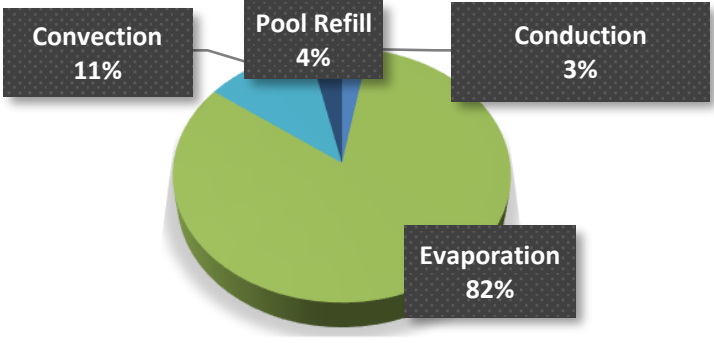

Figure 3: Recreation Building: Pool Energy Breakdown. Figure 4 shows the breakdown of the building's cooling load. As expected, the largest cooling load is the dehumidification and space cooling for the pool. This shows that there is a significant of heat recovery potential from cooling, where the heat rejected from cooling can be used for heating. The high cooling load affects the TEUI of the building as it results from a significant use of electricity. One way to minimize the load could be the addition of a pool cover at night, which would reduce evaporative losses.

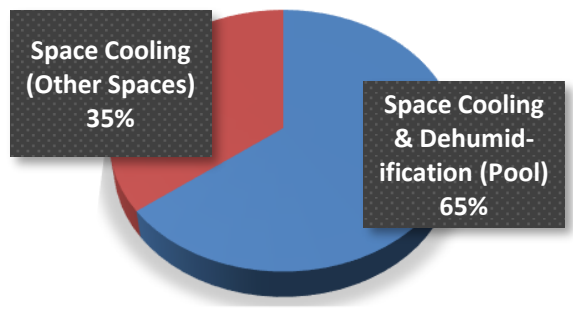

Figure 4: Recreation Building: Cooling Load Breakdown.

\section{Building Energy Use Breakdown}

Figure 5 show the energy use breakdown of the preliminary design. The TEUI of the building is 229 $\mathrm{kWh} / \mathrm{m}^{2}$. The largest contributors to the TEUI are electric heating and cooling, interior fans, and interior lighting. The GHGI is 5 etonnes $\mathrm{kgCO}_{2} / \mathrm{m}^{2}$. The TEDI for whole building and residential spaces are $201 \mathrm{kWh} / \mathrm{m}^{2}$ and 57 $\mathrm{kWh} / \mathrm{m}^{2}$, respectively. The preliminary design is meeting the TEUI and GHGI requirements, but not the TEDI requirements.

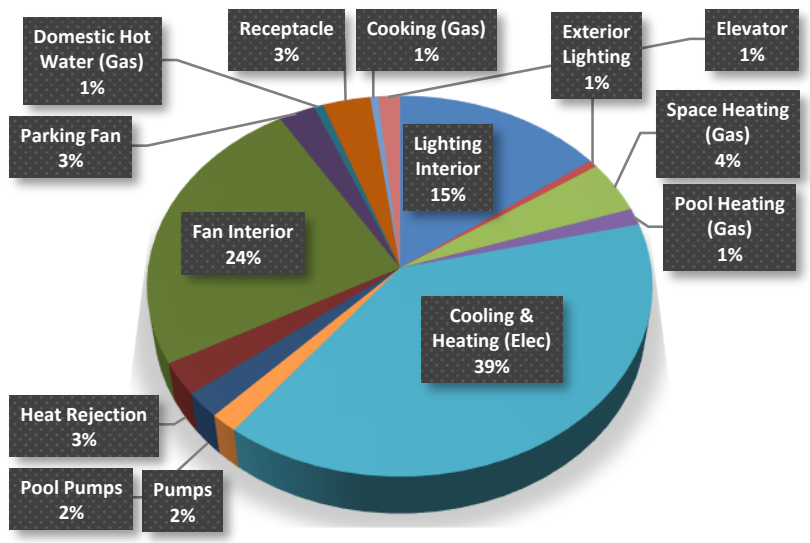

Figure 5: Preliminary Design: Energy Use Breakdown.

\section{Energy Efficiency Measures}

Most of the energy efficiency measure (EEMs) (Table 4) that were investigated aimed to reduce the TEDI of the building. Additional EEMs were tested to evaluate their cost-benefit potential with regard to their impact on the TEUI, TEDI, and GHGI.

Table 4: List of EEMs.

\begin{tabular}{|c|c|}
\hline $\begin{array}{c}\text { Building } \\
\text { Component }\end{array}$ & EEM \\
\hline Mechanical & $\begin{array}{l}\text { - Electric back up boilers } \\
\text { - Suite HRV (residential tower only) }\end{array}$ \\
\hline Envelope & $\begin{array}{ll}\text { - } & \text { Roof: R-40 (RSI 7.0), R-60 (RSI 10.6) } \\
\text { - Walls: R-30 (RSI 5.3), R-45 (RSI 7.9) } \\
\text { - Windows: U-0.33 (USI 1.9), U-0.25 (USI } \\
\text { 1.4) } \\
\text { - Higher airtightness: } 0.1 \text { L/s-m² facade } \\
\text { (residential tower only) }\end{array}$ \\
\hline Lighting & - LED lighting (excluding pool and gym) \\
\hline DHW & $\begin{array}{l}\text { - Low flow fixtures } \\
\text { - Drain water heat recovery }\end{array}$ \\
\hline Pool & - Pool cover during unoccupied hours \\
\hline
\end{tabular}

\section{Impact of Measures}

Figure 7 to Figure 6 shows the TEUI, GHGI, and TEUI savings for each EEM based on the preliminary design energy model. Pool cover, triple glazed windows (U0.25 ), and LED lighting provide the highest TEUI and GHGI savings. Pool cover, double glazed windows (U$0.33)$ and triple glazed windows (U-0.25) provide the highest TEDI savings.

Figure 6: EEM TEDI Savings.

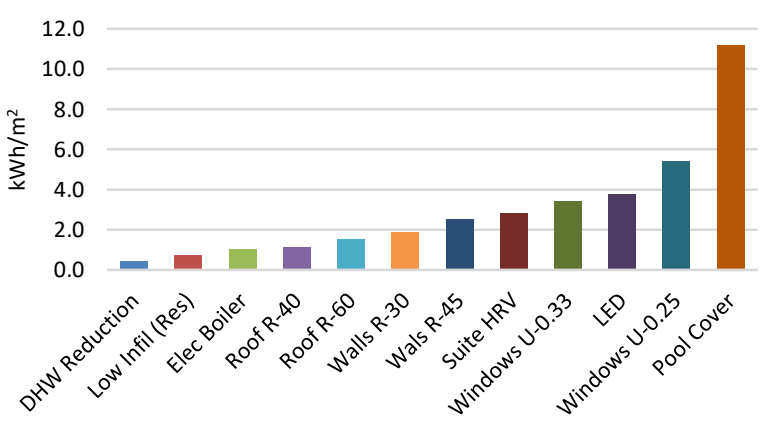

Figure 7: EEM GHGI Savings.

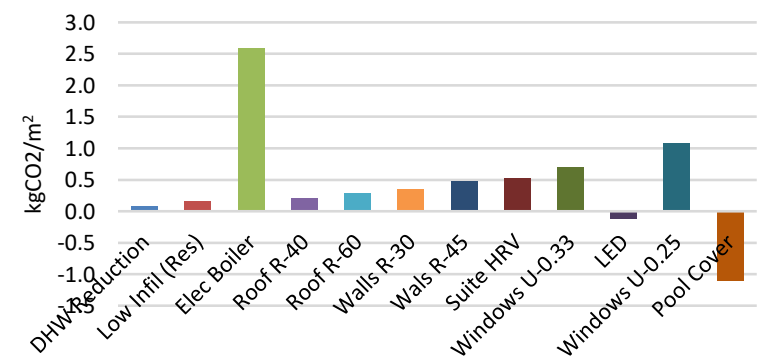


Figure 8: EEM TEDI Savings.

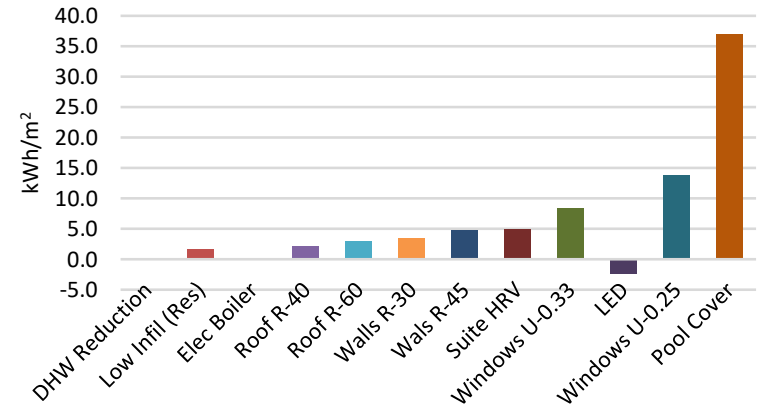

Parametric Design Analysis Results

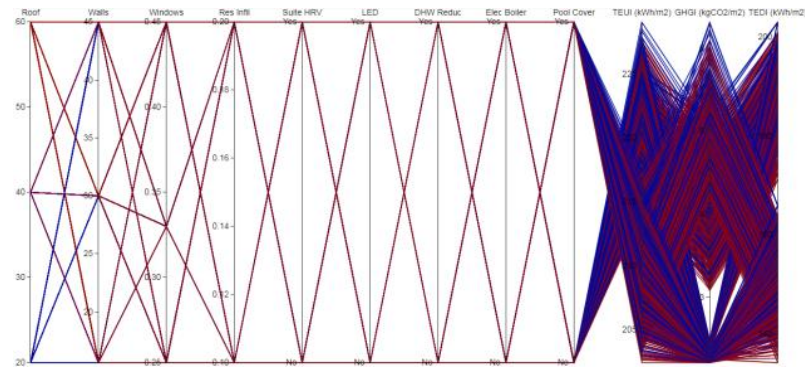

Figure 9 shows a full set of results of every combination of EEMs possible (i.e. 1728 simulations). Figure 10 shows the Design Options that meet the TEDI requirement for the whole building (i.e. $174 \mathrm{kWh} / \mathrm{m}^{2}$ ). Since there are still lines that go through every EEM option, there are no EEMs that are completely ruled out. only some specific combinations of EEMs. This means that there will be trade-off situations, where if you pick one EEM, you may not be able to pick another one.

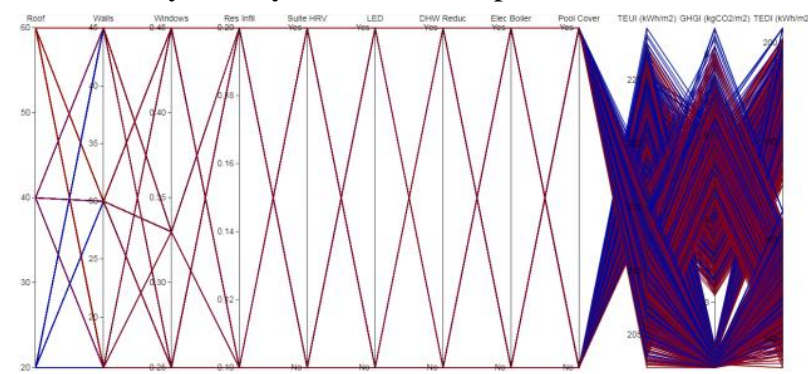

Figure 9: Parametric Design Analysis - All Results.

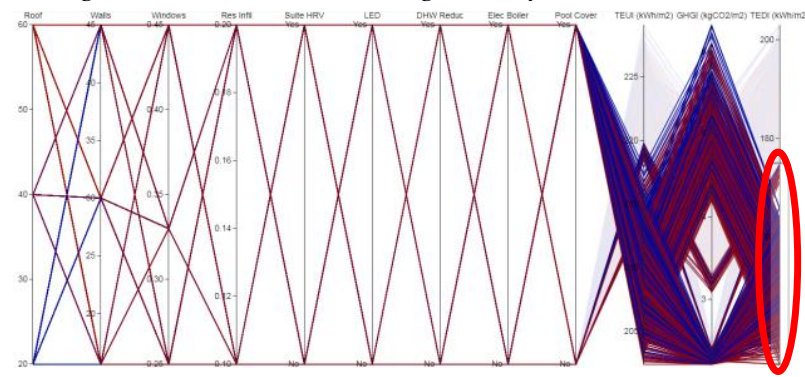

Figure 10: Design Options - Meets TEDI Requirement.

An Energy Workshop was held to share the results of the analysis with the design team and clients. At the workshop, the financial implications and feasibility of implementation for each EEM was discussed. The team was keen on implementing the following EEMs:

- Double glazed windows (U-0.34, SHGC 0.4)
- LED lighting (excluding pool and gym)

- R-60 Roof

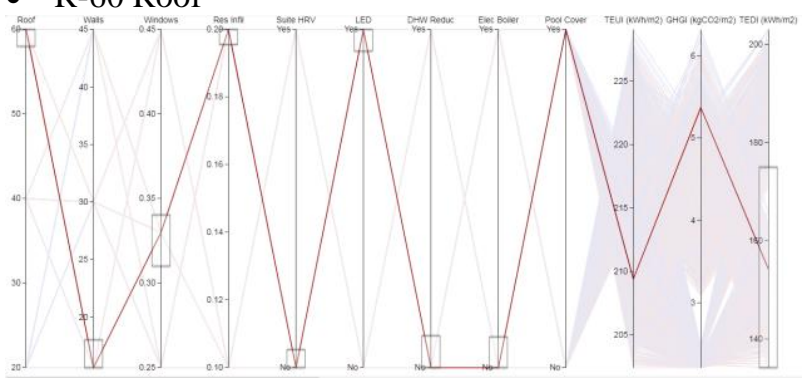

Figure 11 shows the EEMs that were chosen to be implemented into the design. Unfortunately, based on their selections, the pool cover must be also implemented in order to meet the TEDI requirement. Pool covers can be expensive to implement as it requires the purchase of the cover system, maintenance of the system, additional training of the pool staff, and extra work time every day to deploy the cover.

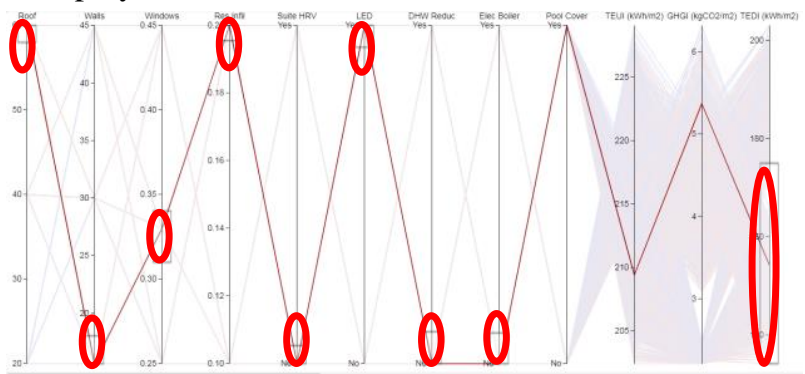

Figure 11: Design Option - Preferred EEMs.

Based on feedback from the Energy Workshop and our parametric analysis, we investigated additional EEMs that could potentially lower the building's TEDI without the use of a pool cover. The following additional EEMs were investigated:

- Lower window-to-wall ratio for residential tower $(30 \%)$

- Dewpoint temperature control for the pool space $\left(18^{\circ} \mathrm{C}\right)$

Since the VBBL energy requirements will be updated during the design phase, the building must meet stricter envelope requirements. Envelope components in the model were updated to meet the ASHRAE 90.1-2016 standard. This will improve the building's TEDI as well.

- Above ground walls: R-11 (Assembly Maximum, Mass, Non-residential)

- Exposed floors: R-17.5 (Assembly Maximum, Mass, Non-residential)

- Slab on grade: F-0.520 (Unheated, Non-residential)

Final Proposed Design

Based on the TEUI, TEDI, GHGI, financial, and feasibility consideration of all EEMs, the team chose the following EEMs to be implemented in the final design:

- Lower window-to-wall ratio (30\%) for the residential tower

- Dewpoint temperature control for pool space $\left(18^{\circ} \mathrm{C}\right)$

- Double glazed windows (U-0.34, SHGC 0.4)

- LED lighting (excluding pool and gym)

- R-60 Roof 
Table 5 shows the TEDI, TEUI, and GHGI for final proposed design. Unfortunately, the building still does not meet the TEDI requirements.

Before considering additional EEMs to be implemented, we delved deeper into how TEDI is calculated. According to the equation for calculating TEDI, the heat recovered from the exhaust air heat recovery coils is not included. Strictly speaking, only the effect of ventilation heat recovery devices is included in the TEDI. In both cases, heat is extracted from the exhaust air stream and is put back into the building, either directly into the air or via heating coils. Therefore, we believe that the effect of exhaust heat recovery coils should be included in the TEDI. This alternative way of calculating TEDI will be confirmed with the City of Vancouver upon submission of the rezoning application.

Table 5 shows the adjusted TEDI in the rightmost column. The proposed design meets the performance limits if the effect exhaust air heat recovery coils are included in the TEDI. The final proposed design meets the performance limits.

Table 5: Performance Limits and Values - Final Design.

\begin{tabular}{|c|c|c|c|}
\hline Metric & $\begin{array}{c}\text { Perform- } \\
\text { ance Limits }\end{array}$ & $\begin{array}{c}\text { Proposed } \\
\text { Design }\end{array}$ & $\begin{array}{c}\text { Proposed } \\
\text { Design } \\
\text { (Adjusted } \\
\text { TEDI) }\end{array}$ \\
\hline $\begin{array}{c}\mathrm{TEUI} \\
\left(\mathrm{kWh} / \mathrm{m}^{2}\right)\end{array}$ & 316 & 223 & 223 \\
\hline $\begin{array}{c}\mathrm{GHGI} \\
\left(\mathrm{kgCO} / \mathrm{m}^{2}\right)\end{array}$ & 58 & 6 & 6 \\
\hline $\begin{array}{c}\mathrm{TEDI} \\
\left(\mathrm{kWh} / \mathrm{m}^{2}\right)\end{array}$ & $\begin{array}{c}174(\text { Whole } \\
\text { Building) } \\
\text { (Residential } \\
\text { Only) }\end{array}$ & $\begin{array}{c}194 \text { (Whole } \\
\text { Building) } \\
54 \\
\text { (Residential } \\
\text { Only) }\end{array}$ & $\begin{array}{c}141 \text { (Whole } \\
\text { Building) } \\
15 \\
\text { (Residential } \\
\text { Only) }\end{array}$ \\
\hline
\end{tabular}

\section{Discussion}

The new rezoning policy requirements has significantly changed the building design practice in Vancouver. Before this policy, it was only required for the building design to with the ASHRAE 90.1 or NECB code. Either paths consist of relative comparisons to a "baseline" or "reference" building in terms of energy cost or energy savings. The new policy requires that the building design meet specific TEUI, TEDI and GHGI targets for residential, retail, hotel, and office buildings. New modelling guidelines (City of Vancouver, 2018) were also introduced by the City, which provide specific model inputs that are missing from the ASHRAE 90.1 or NECB modelling guidelines.

Moving away from just energy or energy cost focused performance targets, the introduction of TEDI and GHGI targets have driven building design to be more envelope and energy source conscious. In the past, building design was able to get away with a mediocre envelope by providing an efficient mechanical system. With the mild climate in Vancouver, it was not necessary to design a high-performance envelope to meet the energy focused targets. With the new TEDI requirement, the design approach has moved to the "passive first" approach, where there is more emphasis in providing a better insulated and sealed building with passive heat recovery features before efficient mechanical systems are considered.

Similarly, energy sources were not considered in building performance before. In Vancouver, natural gas systems were often specified in designs as it is a low-cost fuel source relative to electricity. With the new GHGI target, designers are motivated to use cleaner energy sources, such as electricity, which, in British Columbia, has minimal associated GHG emissions since it's generated from hydroelectric stations. Conversely, natural gas has an emission factor that is approximately 14 times higher than electricity. However, even though electricity may be better for the environment, it is a costly fuel source (i.e. 3 times more expensive than gas). Due to GHG and cost considerations, the design approach has shifted to either: minimizing the need for fuel by using the "passive first" approach and/or utilizing efficient mechanical systems such as heat pumps.

These new targets have added a layer complexity to the design process. Every measure that is considered must be weighted in terms of energy, thermal demand, GHG emissions, and financial implications. Parametric Design Analysis is a useful tool is determining which combination of EEMs are the best for the project by considering all those metrics and ensuring that the optimal design can be achieved.

\section{Conclusion}

In our work, we have analyzed design solutions for achieving the TEUI, TEDI, and GHGI performance targets set by the City of Vancouver's new Green Building Rezoning Policy. Namely, we utilized Parametric Design Analysis (PDA) to investigate the best combination of energy efficient measures to implement for a mixed-use recreational facility that includes a pool, gym, multipurpose, and residential spaces.

Our proposed methodology for finding cost-effective solutions for retrofit or new construction projects with complex building performance targets has proven to be effective by the study presented in this paper and (Chan et al., 2018). As performance targets become more complex for future building design projects, it is critical to utilize this method to ensure that all design options are analysed and optimum cost-effective solutions can be found.

\section{References}

Al-ajmi, F., Alkhamis, M. T., \& Alsaeid, H. M. (2017). Parametric simulation for energy efficient building design of Kuwaiti domestic buildings. Journal of Buildings and Sustainability, 1(1), 48-60.

Attia, S., Gratia, E., De Herde, A., \& Hensen, J. L. (2012). Simulation-based decision support tool for early stages of zero-energy building. Energy and Buildings, 49, 2-15.

Chan, J., Irwin, R., Frisque, A., \& Dunford, E. (2018). Cost-effective net-zero energy/GHG solutions 
for retrofit projects using parametric whole building energy simulations. eSim 2018. Montreal, Canada.

City of Vancouver. (2015). Greenest City 2020 Action Plan, Part Two: 2015-2020. Vancouver, BC, Canada.

City of Vancouver. (2018). Energy Modelling Guide. Planning, Urban Design and Sustainability Department. Retrieved from https:/guidelines.vancouver.ca/E006.pdf

City of Vancouver. (2018). Green Buildings Policy for Rezoning - Process and Requirements.

IES Virtual Environment. (2019, February). How can I model swimming pool gains. Retrieved from IESVE:

https://www.iesve.com/support/knowledgebase/ $\mathrm{faq} / 2116$

Iqbal, I., \& Al-Homoud, M. (2007). Parametric analysis of alternative energy conservation measures in an office building in hot and humid climate. Building and Environment, 42, 2166-2177.
Kerdan, I., Raslan, R., \& Ruyssevelt, P. (2015). Parametric study and simulation-based exergy optimization for energy retrofits in buildings. 28th International Conference on Efficiency, Cost, Optimization, Simulation and Environmental Impact of Energy Systems. Pau, France.

Lee, S. H., Hong, T., Piette, M., Sawaya, G., Chen, Y., \& Taylor-Lang, S. C. (2015). Accelerating the energy retrofit of commercial buildings using a database of energy efficiency performance. Energy, 90, 738-747.

Parker, A., Benne, K., Brackney, L., Hale, E., Macumber, D., Schott, M., \& Weaver, E. (2014). A Parametric Analysis Tool for Building Energy Design Workflows: AApplication to a Utility Design Assistance Incentive Program. ACEEE Summer Study on Energy Efficiency in Buildings, (pp. 263-274). Pacific Grove, CA. 